\title{
Fish oil in the treatment of ulcerative colitis
}

\author{
CÓ'MORÁIN, MD, MSc, FRCPC, A TOBIN, MRCRCP, T MCCOLL, MD, Y SUZUKI, MD
}

\begin{abstract}
Patients with active ulcerative colitis have increased levels of leukotriene $\mathrm{B}_{4}$ in their rectal mucosa. Eicosapentaenoic acid (EPA) competitively inhibits the cyclo-oxgenase pathway and reduces the formation of cyclooxygenase pathway products. EPA is a good substrate for lipoxygenase enzymes and is efficiently converted to leukotriene $\mathrm{B} 5$, which is less biologically active. The conversion of EPA to leukotriene $\mathrm{B}_{5}$ is as efficient as that of arachidonic acid to leukotriene B4. Two pilot studies showed benefit of EPA in the treatment of ulcerative colitis. Two of three controlled studies suggest that EPA is more effective than placebo in the treatment of active chronic ulcerative colitis. The mechanism of action is probably reduction of leukotriene $B_{4}$, but EPA could increase cell and lysosomal membrane stability, or it may exert its effect by reducing interleukin-1. More controlled studies and detailed investigation into the mode of action of EPA are required. Can J Gastroenterol 1990;4(7):420. 423
\end{abstract}

Key Words: Eicosapentaenoic acid, Fish oil, Ulcerative colitis

\section{L'huile de poisson dans le traitement de la colite ulcéreuse}

RESUME: On détecte des niveaux accrus de leucotriènes $B_{4}$ dans la muqueuse rectale des patients atteints de colite ulcéreuse en évolution. L'acide eicosapentaënoïque (EPA) inhibe la voie cyclo-oxygénase et réduit la formation des produits qui en sont issus. L'EPA est un bon substrat pour les enzymes de lypoxygénase et il se convertit efficacement en leucotriènes B5, dont l'activité biologique est moindre. Cette conversion est aussi efficace que celle de l'acide arachidonique en leucotriène $\mathrm{B}_{4}$. Deux études pilotes ont démontré les avantages de l'EPA dans le traitement de la colite ulcéreuse. Deux de trois étides contrôlées suggèrent que l'EPA est plus efficace que le placebo dans le traitement de la colite ulcéreuse chronique en évolution. En plus d'effectuer la conversion décrite précédemment, le mécanisme d'action augmenterait la stabilité de la cellule et de la membrane lysosomale, et il pourrait aussi réduire l'interleukine-1. Il est nécessaire d'effectuer un plus grand nombre d'essais contrôlés et des études détaillées sur l'action de l'EPA.

Department of Gastroenterology, Meath/Adelaide Hospitals, Dublin, Ireland

Correspondence and reprints: Dr C ÓMoráin, Department of Gastroenterology, Meath/Adelaide Hospitals, Dublin 8, Ireland
$\mathrm{T}$ HE PATHOGENESIS OF ULCERATIVE colitis remains obscure. A striking characteristic of active ulcerative colitis is the dense infiltration of inflam. matory cells, especially neutrophils, in. to the lamina propria of the diseased colon. A prominent product of arachidonic acid metabolism in neutrophils is leukotriene $B_{4}$ generated via the 5 -lip. oxygenase pathway $(1,2)$. This is a potent chemotactic agent, with activity at concentrations as low as $1 \mathrm{nM}(3)$. Leukotriene $\mathrm{B}_{4}$ induces neutrophil ag. gregation, increases microvascular permeability in the presence of neutro. phils, and is a weak inducer of lysosomal enzyme release $(4,5)$.

Patients with active ulcerative coli. tis have increased levels of leukotriene $\mathrm{B}_{4}$ in their rectal mucosa. These levels fall when the disease remits (6). Nonsteroidal anti-inflammatory drugs (NSAIDs) can induce colitis de novo and exacerbate pre-existing colitis (7). It is thought that NSAIDs inhibit the cyclo-oxygenase pathway and cause an increase in leukotriene B4. Sulphasala. zine, the mainstay of treatment of ul. cerative colitis, may exert its therapeutic effect by reducing leukotriene $B_{4}$ (8).

Fish oil in the form of eicosapenta. enoic acid (EPA) competitively inhi. bits the cyclo-oxygenase pathway, thus reducing the formation of cyclo. 
oxygenase pathway products (9). EPA is a good substrate for the lipoxygenase enzyme and is efficiently converted to leukotriene $\mathrm{B}_{5}(10)$. Leukotriene $\mathrm{B}_{5}$ is far less active than leukotriene $\mathrm{B}_{4}$ in vitro and in vivo $(11,12)$. In Europe the lowest incidence of ulcerative colitis is found in Spain, and the highest in north-eastern Europe, which may reflect fish consumption. Studies in other inflammatory diseases such as theumatoid arthritis and psoriasis using $2.5 \mathrm{~g}$ EPA daily have demonstrated clinical improvement $(13,14)$.

\section{PILOT STUDIES OF FISH OIL IN ULCERATIVE COLITIS}

In a small uncontrolled study the authors treated six patients with chronic active ulcerative colitis with 3 to $4 \mathrm{~g}$ EPA per day; these patients went into remission (15).

There was a significant fall in neutrophil chemoluminescence during treatment in patients, whereas no change was observed in the control group. Neutrophil leukotriene $\mathrm{B}_{4}$ levels fell significantly during treatment. Serum from patients receiving fish oil wab significantly less chemotactic for neutrophils compared with control serum. EPA inhibited neutrophil chemotaxis and chemoluminescence in vitro. The omega- 3 fatty acids which occur naturally in fish oils may exert a beneficial effect by decreasing the production of inflammatory mediators.

In another recently published trial, the efficacy of $n$-3-omega fatty acid was evaluated in the treatment of $10 \mathrm{pa}$ tients with mild to moderate ulcerative colitis who had either failed (nine) or refused (one) conventional treatment (16). Seven showed moderate to marked improvement. Steroid dosage could be reduced in four of the five patients on prednisone. Three showed little or no improvement. MAXEPA, the form of EPA used in these studies, contains other substances including docosahexaenoic acid, which by itself could be beneficial prior to conversion to EPA, and vitamin E (17). Vitamin E is a physiological radical scavenger which could also help the colitis. Metabolism of arachidonic acid represents a lipid peroxidation which may be miti- gated by superoxide production. It is possible that vitamin E serves as a regulatory mechanism for arachidonic acid oxygenation products. Patients are required to take between 15 and 18 tablets per day to obtain a clinical response. No side effects were reported because of the large numbers of tablets, but it is difficult to be sure of compliance.

\section{CONTROLLED STUDIES OF FISH OIL IN ULCERATIVE COLITIS}

Stenson and colleagues (18) reported a controlled multicentre trial of MAXEPA in the treatment of chronic active ulcerative colitis. Patients were randomized to receive either EPA or corn oil. In their global assessment of 19 patients who received MAXEPA, nine improved, one worsened and nine remained the same. Of the 18 patients who received corn oil, only three improved, three worsened and 12 remained unchanged. A similar positive trend was seen in endoscopy results.

Hawthorne and colleagues (19) presented the results of 87 patients with ulcerative colitis and stratified them according to disease activity into active or quiescent groups. Patients were given H1 EPA or placebo. Sixteen of the 28 patients with active disease who received H1 EPA went into remission, compared with 19 of 27 with active disease on placebo. In patients who were in remission, 15 of 35 relapsed on H1 EPA compared to 11 of 34 on placebo. This study did not appear to show any benefit of fish oil in patients with ulcerative colitis. However, these patients were given H1 EPA which contained other ingredients, including linoleic acid. There are also difficulties in assessing remissions and exacerbations. The number of bowel movements, used as an indicator of disease activity, is not always reliable. Up to $27 \%$ of patients with active ulcerative colitis have hard formed stools. Other symptoms common in active ulcerative colitis that are difficult to evaluate include urgency, incomplete evacuation, tenesmus, pain, soreness and incontinence (20). Encouraged by their earlier results, the authors have conducted a double-blind, crossover, controlled trial of 23 patients with chronic active ulcerative colitis considered to warrant additional treatment. Four months of EPA $3.8 \mathrm{~g}$ daily were compared with four months of placebo (corn oil) separated by a six week washout period (21). This EPA was 93\% pure, mainly in the form of an ethyl ester. Study endpoints were completion of treatment or deterioration requiring high dose steroids. Ten males and 13 females (mean age 36 years) were entered. Nine patients had total colitis and 14 leftsided colitis. Twenty-one patients received sulphasalazine or 5-aminosalicylic acid, and six received 10 to $20 \mathrm{~g}$ steroids per day. Patients were assessed at weekly intervals for general wellbeing (well, unwell or poor), bleeding/ mucus (absent, mild or severe), bowel frequency (fewer than three, three to five or more than five), pain (none, mild or moderate). Patients had to improve in two of these parameters to be considered improved. Thirteen patients were given EPA as first treatment. Of these, 10 improved, two remained unchanged and one worsened. Of the 10 who received corn oil, three improved, two remained unchanged and five worsened. In the second phase of treatment, only seven crossed over to EPA. Three of these improved, three remained the same and one worsened. Of the 10 who crossed over to placebo, six worsened and five remained the same.

Overall, 13 of 20 patients improved compared to three of 20 who received corn oil. Two worsened on EPA compared to 10 on placebo. These results suggest that fish oil may be a useful adjunctive treatment for chronic active ulcerative colitis.

\section{MECHANISM OF ACTION OF EPA}

The most likely mechanism by which EPA exerts its effect is reduction of leukotriene $\mathrm{B}_{4}$ production in the rectal mucosa. However, the increased levels of $\mathrm{B}_{4}$ in active ulcerative colitis and the decreased levels found in the quiescent phase may reflect the neutrophil infiltrate found in active disease. Other enzyme markers of neutrophils such as vitamin $\mathrm{B}_{12}$ binding protein, 
lysozyme and myeloperoxidase are also raised in active ulcerative colitis, and these levels fall in this quiescent phase in parallel with histological improvement (22). Also, enzyme markers of lysosomes, n-acetyl-beta-glucosaminidase, acid phosphatase and beta-glucuronidase, were decreased in the rectal mucosa in both active and quiescent ulcerative colitis (23). Lysosomal acid hydrolases have been implicated pathogenically in several diseases, particularly inflammatory joint disease (24), systemic lupus erythematosus (25) and possibly chronic lung disease - particularly that associated with antitrypsin deficiency (26). A specific decrease in lysosomal enzymes may play a role in the pathogenesis of ulcerative colitis. The lysosome may be disrupted by a variety of mechanisms such as viral infection, ischemia, toxic metabolites,

\section{REFERENCES}

1. Borgeatt P, Samuelsson B. Transformation of arachidonic acid by rabbit polymorphonuclear leucocytes. J Biol Chem 1979;254:2643-6.

2. Samuelsson B. Leukotrienes: Mediators of immediate hypersensitivity reactions and inflammation. Science 1983;220:568-75.

3. Goebel EJ, Pickett WC. The human PMN leucocyte chemotactic activity of complex hydroxy-eicosaterraenoic acids (HETE). J Immunol 1980;125:1789-91.

4. Arfors K, Hammarstrom S, Lindgren J, et al. Leukotrienes promote plasma leakage and leukocyte adhesion in postcapillary venules: In vivo effects with relevance to the acute inflammatory response. Proc Natl Acad Sci USA 1981;78:3887-91.

5. Bokoch GM, Reed PW. Effect of various lipoxygenase metabolites of arachidonic acid on degranulation of polymorphonuclear leukocytes. J Biol Chem 1981;256:5317-20.

6. Sharon P, Ligumsky M, Rachmilewitz $\mathrm{D}$, Zor U. Role of prostaglandins in ulcerative colitis. Enhanced production during active disease and inhibition by sulfasalazine. Gastroenterology 1978;75:638-40.

7. Rampton DS, Hawkey CJ. Prostaglandins and ulcerative colitis. Gut 1984;25:1399-413.

8. Lauritzen K, Hansen J, Byizer P, Bukhave K, Rask-Madsen J. Effects of sulphasalazine and disodium azodisalicylate on colonic $\mathrm{PGE}_{2}$ con- endotoxin, antigen-antibody complexes and leukotriene $\mathrm{B}_{4}$, resulting in intracellular digestion and ultimate cell death. The fall in leukotriene $\mathrm{B}_{4}$ levels induced by EPA may lead to more stable lysosomes $(4,5)$.

Reduced neutrophil chemoluminescence may reflect an effect of fish oil on membrane lipid composition. Fish oil may alter membrane receptor expression and the consequent binding of complement-coated zymosan particles with the complement receptor of the neutrophil. Interestingly, neutrophil chemoluminescence in rheumatoid arthritis patients has also been reported to be reduced (27). In this study and the authors', this reduction coincided with a significant improvement in each of the clinical variables studied.

Interleukin-1 levels have been reported to be raised in inflammatory bowel disease (28). Interleukin-1 has a wide range of biological activities, including induction of hepatic acute phase protein synthesis, prostanoid synthesis, activation of lymphocytes and neutrophils, and induction of col. lagen release by fibroblasts.

Healthy volunteers who were given EPA had decreased production of interleukin-1 by peripheral circulating monocytes (29). Preliminary work from the authors' laboratory suggests that interleukin-1 levels are decreased following EPA treatment in patients with ulcerative colitis. These results suggest that EPA is a useful adjunctive treatment of ulcerative colitis.

Further controlled studies are required, and a detailed investigation of the mode of action of EPA will provide further information as to the etiology of ulcerative colitis.

centration determined by equilibrium in vivo dialysis of faeces of patients with ulcerative colitis and healthy controls. Gut 1984;25:1271-8.

9. Needleman P, Raz A, Minkes M, Ferrendelli]A, Sprecher H. Triene prostaglandins: Prostacyclin and thromboxane biosynthesis and unique biological properties. Proc Natl Acad Sci USA 1979;76:944-8.

10. Yokogama C, Mizuno K, Mitachi H, Yoshimoto T, Yamamoto S, PaceAsciak CR. Partial purification and characterization of arachidonate 12 . lipoxygenase from rat lung. Biochim Biophys Acta 1983;750:237-43.

11. Prescott SM. The effect of eicosapentaenoic acid on leukotriene B production by human neutrophils. J Biol Chem 1984;259:7615-21.

12. Terano T, Salmon JA, Moncada S. Biosynthesis and biological activity of leukotriene B5. Prostaglandins 1984;27:217-32.

13. Timchalk M, Beeler D, Lininger L, et al. Fish-oil fatty acid supplementation in active rheumatoid arthritis. Ann Intern Med 1987;106:497-502.

14. Kragballe K. Dietary supplementation with a combination of N-3 and N-6 fatty acids marine super gamma oil improves psoriasis. Acta Dermatol Venerol 1989;69:265-8.

15. McCall TB, O'Leary D, Bloomfield J, ÓMoráin CA. Therapeutic potential of fish oil in the treatment of ulcerative colitis. Aliment Pharmacol Ther 1989;3:415-24.
16. Salomon P, Kornbluth AA, Janowitz HD. Treatment of ulcerative colitis with fish oil n-3-w-fatty acid: An open trial. J Clin Gastroenterol 1990;12:15?. 61.

17. Donowitz M. Arachidonic acid metabolites and their role in inflammatory bowel disease. An update requiring addition of a pathway. Gastroenterology 1985;88:580-2.

18. Stenson WF, Cort D, Beeken W, Rodgers J, Burakoff R. A trial of fish oil supplemented diet in ulcerative colitis. Gastroenterology 1990;98:A475.

19. Hawthorne AB, Daneshmend TK, Hawkey CJ, et al. Fish oil in ulcerative colitis: Final results of a controlled clinical trial. Gastroenterology 1990;98:A174.

20. Rao SSC, Holdsworth CD, Read N. Symptoms and stool patterns in patients with ulcerative colitis. Gut 1988;29:342-5.

21. Tobin A, Suzuki Y, ÓMoráin C. A controlled double-blind crossover study of eicosapentaenoic acid (EPA) in chronic ulcerative colitis. Gastroenterology 1990;98:A207.

22. Ó'Moráin CA. Crohn's Disease, Treatment and Pathogenesis. Boca Raton: CRC Press, 1987:240.

23. Levi AJ, Peters TJ, Ó'Moráin CA, Smethhurst P. Organelle pathology in ulcerative colitis and Crohn's disease with special reference to the lysosome alterations. Gut 1984;25:455-9.

24. Deykin D, Parris EE, Weissmann G. Lysosomal mechanisms of tissue injury in arthritis. N Engl J Med 
1972;286:141-2.

25. Weissman G. The role of lysosomes in inflammation and disease. Annu Rev Med 1967;18:97-112.

26. Allison AC. Lysosomes and the toxicity of particular pollutants. Arch Intern Med 1971;128:131-9.

27. Magaro M, Altomonte L, Zoli A, et al. Influence of diet with different lipid composition on neutrophil chemiluminescence and disease activity in patients with rheumatoid arthritis. Ann Rheum Dis 1988;47:793-6,

28. Suzuki Y, Tobin A, Quinn D, ÓMoráin C. Interleukin 1 levels in Crohn's disease. Eur J Clin Hepatol
Gastroenterol. (In press)

29. Spur BW, Robinson DR, Corey EJ, et al. Effect of dietary enrichment with eicosapentaenoic and docosahexaenoic acid on in vitro neutrophil and monocyte leukotriene generation and neutrophil function. N Engl J Med 1985;312:1212-24. 


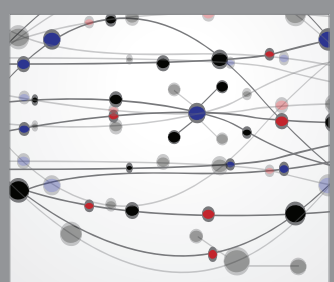

The Scientific World Journal
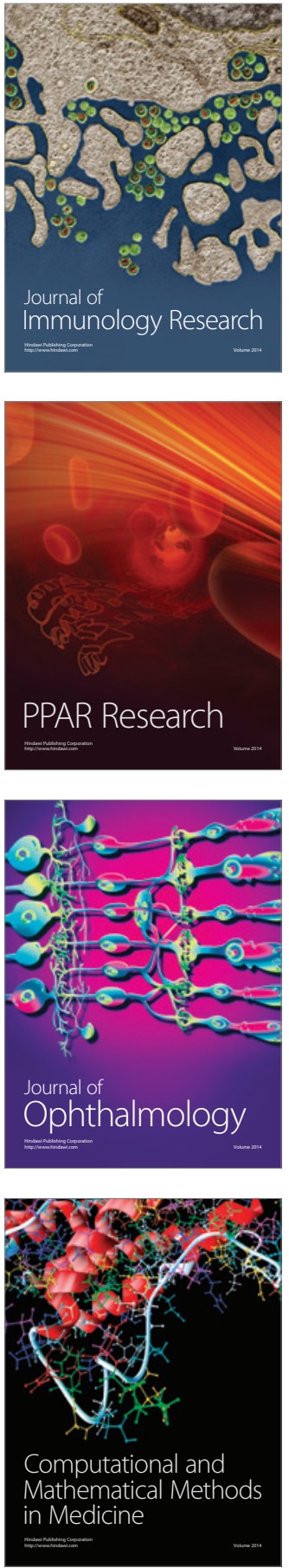

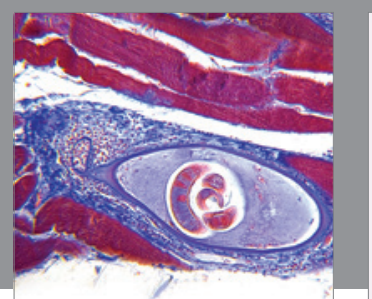

Gastroenterology Research and Practice

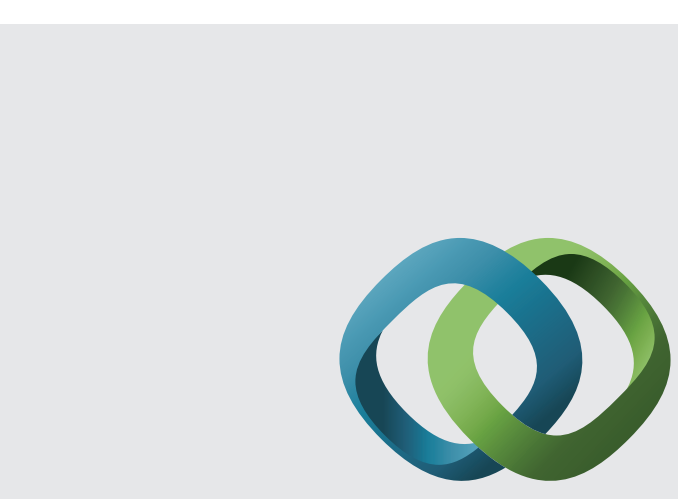

\section{Hindawi}

Submit your manuscripts at

http://www.hindawi.com
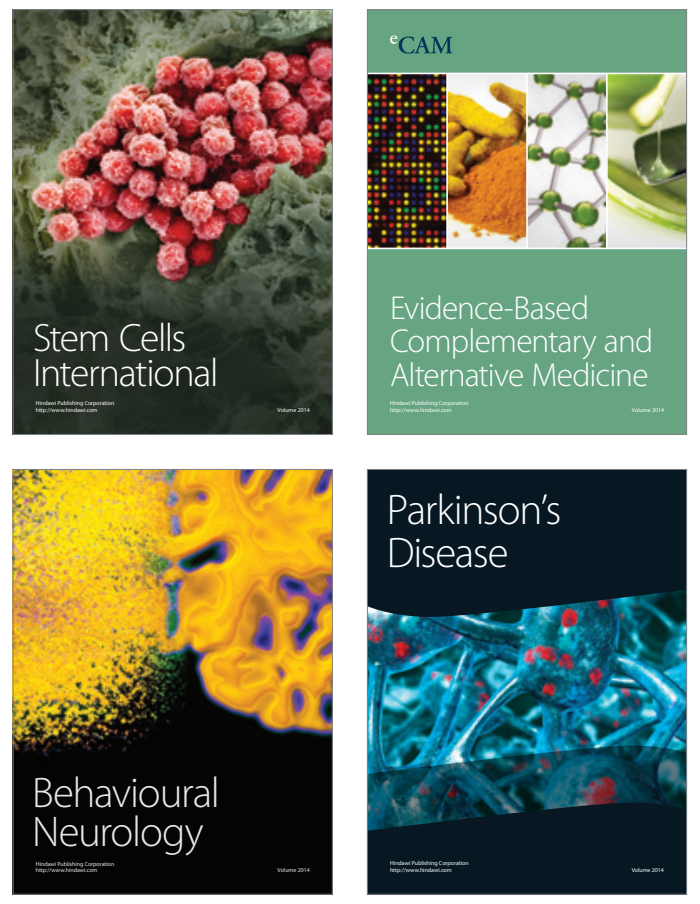
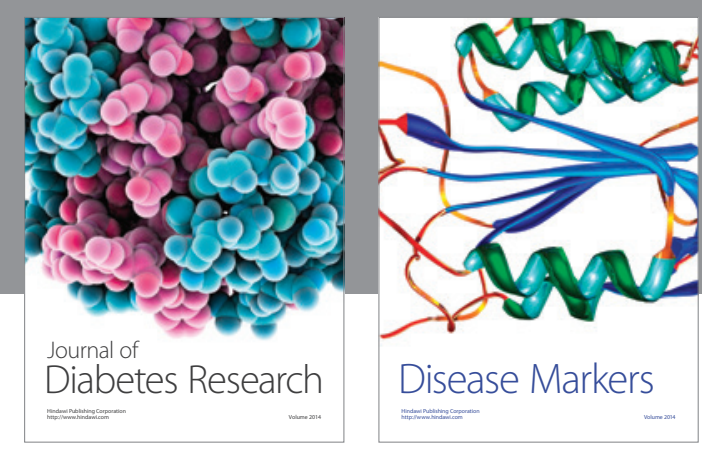

Disease Markers
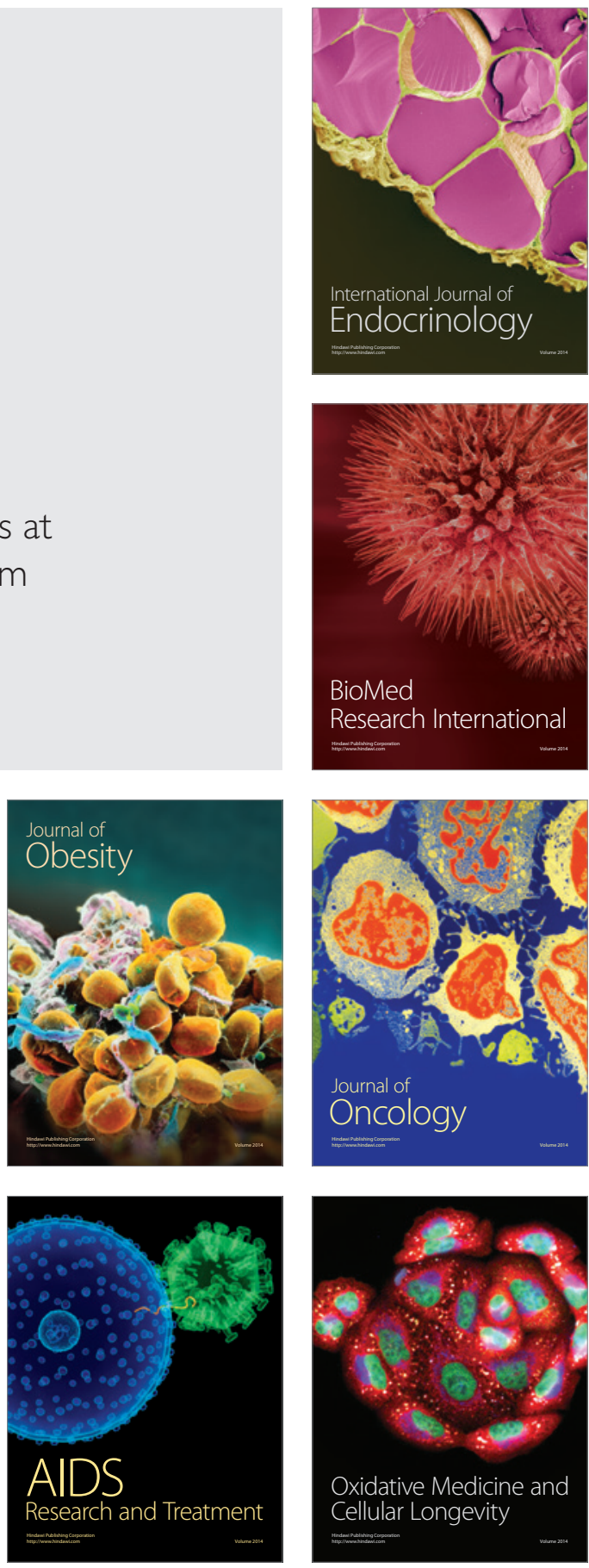